\title{
STUDY ON THE CONVERSION OF LAPAROSCOPIC CHOLECYSTECTOMY OWING TO PER OPERATIVE COMPLICATIONS
}

\author{
Selvaraj Vishnuvarthan ${ }^{1}$, Saminathan Suganya ${ }^{2}$
}

${ }_{1}^{1}$ Assistant Professor, Department of General Surgery, KFMSR, Othakalmandapam, Tamilnadu, India.

${ }^{2}$ Assistant Professor, Department of Anatomy, KFMSR, Othakalmandapam, Tamilnadu, India.

\begin{abstract}
\section{BACKGROUND}

In the modern medical era, laparoscopic approach to surgical conditions has reached to a height that it is performed even for malignant conditions. The minimal access surgery which has grown up from minimally invasive surgery has given us the faith that nearly all surgeries can be done by laparoscopy. The first laparoscopic cholecystectomy was done by Prof. Dr. Med Erich Muhe of Germany in the year 1985. About ten lakh cholecystectomies are performed ever year, of which $96 \%$ are done by laparoscopic method. Laparoscopic cholecystectomy is the most common laparoscopic procedure. By number of studies and research works, it is stated that laparoscopic cholecystectomy is superior to conventional open method because of its advantages like smaller incisions, early recovery, less post-operative pain and hospital stay with better cosmesis. However, laparoscopic cholecystectomy also has got its own disadvantages and complications. In 1992, an NIH consensus conference held in Bethesda approved laparoscopic cholecystectomy as the treatment of choice for symptomatic cholelithiasis. Conversion to open technique is a major morbidity of laparoscopy, as it loses its supremacy over open technique once the conversion takes place. With growing experience of laparoscopic cholecystectomy and completion of the learning curve, the indications for laparoscopic cholecystectomy have been extended approaching that of open cholecystectomy. Complications of laparoscopic cholecystectomy have been minimised to as low as 2 - $6 \%$. However, a substantial proportion of patients had to be converted to open surgery because of technical difficulties or intraoperative complications. Conversion rates of $2.6 \%$ to $14 \%$ had been described in different studies. The factor to be considered with conversion is that it should never be considered a complication, but rather a correct judgement by the surgeon.
\end{abstract}

The aims of the present study are:

1. To study the incidence of conversion of laparoscopic cholecystectomy.

2. To analyse the reasons for the conversion of laparoscopic cholecystectomy owing to per operative complications like-
a) Arterial injury,
b) Hepatobiliary tract injury,
c) Dense adhesions,
d) Aberrant anatomy,
e) Technical issues.

\section{MATERIALS AND METHODS}

This prospective observational study was conducted in patients who underwent laparoscopic cholecystectomy from November 2016 to November 2017 in the Department of General Surgery, Karpagam Faculty of Medical Sciences and Research, Coimbatore. There were totally 98 patients, of which 36 were males and 62 were females. The study has been done after the patient's informed consent. All these patients were evaluated in a proper manner as given in the proforma and had been assessed pre-operatively and operated under perfect anaesthetic fitness. This study mainly focussed on the patients who had been converted to open method. They were analysed further regarding the reasons for conversion to open method due to per-operative complications.

\section{RESULTS}

From November 2016 - November 2017, a total of 98 patients had undergone laparoscopic cholecystectomy in the Department of General Surgery, Karpagam Faculty of Medical Sciences and Research, Coimbatore. Out of 98 patients who underwent laparoscopic cholecystectomy, 13 patients (13.26\%) were converted to open cholecystectomy owing to per-operative complications. All patients underwent cholecystectomy as an elective case. Though some morbidity was there in terms of post-operative complications, which we are not analysing, no mortality was reported.

\section{CONCLUSION}

After analysing the results of our study, we conclude that the incidence of conversion of laparoscopic cholecystectomy is $13.26 \%$. The reasons for conversion in descending order of frequency are: 1. Dense adhesions (5.1\%), 2. Difficult anatomy around Calot's triangle (3.06\%), 3. Arterial injury (3.06\%), 4. Hepatobiliary injury (1.02\%) and 5. Technical issues (1.02\%).

\section{KEY WORDS}

Laparoscopic Cholecystectomy, Cholelithiasis, Per-Operative Complications, Bile Duct, Cystic Artery, Adhesions, Calot's Triangle. HOW TO CITE THIS ARTICLE: Vishnuvarthan S, Suganya S. Study on the conversion of laparoscopic cholecystectomy owing to per operative complications. J. Evolution Med. Dent. Sci. 2018;7(38):4152-4156, DOI: 10.14260/jemds/2018/929

\section{BACKGROUND}

In the modern medical era, laparoscopic approach to surgical conditions have reached to a height that it is performed even for malignant conditions. The minimal access surgery, which has grown up from minimal invasive surgery has given us the faith that nearly all surgeries can be done by laparoscopy. The first laparoscopic cholecystectomy was done by Prof. Dr. Med Erich Muhe of Germany in the year 1985. About ten lakh cholecystectomies are performed ever year, of which $96 \%$ are done by laparoscopic method. Laparoscopic cholecystectomy 
is the most common laparoscopic procedure that is done today in the modern medical era.

By number of studies and research works, it is stated that laparoscopic cholecystectomy is superior to conventional open method because of its advantages like smaller incisions, early recovery, less post-operative pain and hospital stay with better cosmesis. However, laparoscopic cholecystectomy also has got its own disadvantages and complications. In 1992, an NIH consensus conference held in Bethesda approved laparoscopic cholecystectomy as the treatment of choice for symptomatic cholelithiasis. Conversion to open technique is a major morbidity of laparoscopy, as it loses its supremacy over open technique once the conversion takes place. With growing experience of laparoscopic cholecystectomy and completion of the learning curve, the indications for laparoscopic cholecystectomy have been extended approaching that of open cholecystectomy.

Complications of laparoscopic cholecystectomy have been minimised to as low as $2-6 \%$. However, a substantial proportion of patients had to be converted to open operation, because of technical difficulties or intraoperative complication. Conversion rates of $2.6 \%$ to $14 \%[1,2,3,4]$ had been described in different studies. The factor to be considered with conversion is that it should never be considered a complication, but rather a correct judgement by the surgeon.

\section{Aim of the Study}

\section{The Aims of the Present Study are-}

1. To study the incidence of conversion of laparoscopic cholecystectomy.

2. To analyse the reasons for the conversion of laparoscopic cholecystectomy owing to per operative complications like-
a) Arterial injury.
b) Hepatobiliary tract injury.
c) Dense adhesions.
d) Aberrant anatomy.
e) Technical issues.

\section{MATERIALS AND METHODS}

This prospective observational study was conducted in the patients who underwent laparoscopic cholecystectomy from November 2016 to November 2017 in the Department of General Surgery, Karpagam Faculty of Medical Sciences and Research. There were totally 98 patients, of which 36 were males and 62 were females. The study has been done after the patient's informed consent. All these patients were evaluated in a proper manner and have been assessed pre-operatively and operated under perfect anaesthetic fitness.

'Financial or Other Competing Interest': None.

Submission 06-08-2018, Peer Review 01-09-2018,

Acceptance 06-09-2018, Published 17-09-2018.

Corresponding Author:

Saminathan Suganya,

2/697, S. R. Nagar,

Mangalam Road,

Tirupur-641687,

Tamilnadu, India.

E-mail: suganss02@gmail.com

DOI: $10.14260 /$ jemds $/ 2018 / 929$
This study focusses only on the patients who have been converted to open method. They were analysed further regarding their reasons for conversion to open method due to per operative complications.

\section{Inclusion Criteria}

1. All patients with symptomatic gallstone disease.

2. Asymptomatic gallstone disease in patients with type 2 DM.

3. Benign gall bladder disease like gallbladder polyp.

\section{Exclusion Criteria}

1. Patients who had undergone previous upper GI surgeries.

2. Patients with known liver diseases.

All the patients admitted in ward with a diagnosis of cholelithiasis in Department of General Surgery, Karpagam Faculty of Medical Sciences and Research in the time period of November 2016 - November 2017 were included in this study. Thorough history and clinical examination was done. Admission baseline blood investigations were done. Liver function test was done in all patients. As per the standard protocol, all patients were treated with medical and surgical care as available in the Institution. All patients were subjected to ultrasonogram abdomen and upper GI endoscopy. CECT abdomen was done in patients with suspected pancreatic/common bile duct pathology. MRCP was done in patients with elevated alkaline phosphatase and dilated $\mathrm{CBD} /$ associated CBD pathology. Consent regarding conversion if necessary was also obtained in all cases.

\section{RESULTS}

From November 2016 - November 2017, a total of 98 patients underwent laparoscopic cholecystectomy in Department of General Surgery, Karpagam Faculty of Medical Sciences and Research. Out of 98 patients who underwent laparoscopic cholecystectomy, 13 patients $13.26 \%$ were converted to open cholecystectomy owing to per-operative complications. Of these 98 patients 36 were males and 62 were females, out of which 6 males and 7 females were converted into open cholecystectomy, i.e. $6.12 \%$ males and $7.14 \%$ females of total cases. When taken in terms of number of males and females who got converted, male and female percentages were $16.66 \%$ and $11.29 \%$ (Table 2 and Chart 2) respectively. The least age patient in our study is 16 and the highest age patient is 70 . The conversion was higher in 40 - 50 years' age group $(46.15 \%$ of total conversion) and was low in 30 - 40 years' age group (15.38\% of total conversion) patients. Conversion was not done in 10 - 20 years' age group and 60 - 70 years' age group patients. Highest number of patients who underwent laparoscopic cholecystectomy were in 30 - 40 years' age group (Table 3).

All patients underwent cholecystectomy as an elective case. Though some morbidity was there in terms of postoperative complications which we are not analysing, no mortality was reported. 
Reasons for Conversion of Laparoscopic Cholecystectomy

\begin{tabular}{|c|c|c|c|}
\hline Reasons & $\begin{array}{c}\text { No. of } \\
\text { Cases }\end{array}$ & $\begin{array}{c}\text { \% of Total } \\
\text { (98) Cases }\end{array}$ & $\begin{array}{c}\text { \% of Converted } \\
\text { (13) Cases }\end{array}$ \\
\hline Dense adhesions & 5 & $5.1 \%$ & $38.46 \%$ \\
\hline $\begin{array}{c}\text { Difficult anatomy } \\
\text { around Calot's }\end{array}$ & 3 & $3.06 \%$ & $23.07 \%$ \\
\hline Arterial injury & 3 & $3.06 \%$ & $23.07 \%$ \\
\hline $\begin{array}{c}\text { Hepatobiliary } \\
\text { injury }\end{array}$ & 1 & $1.02 \%$ & $7.69 \%$ \\
\hline $\begin{array}{c}\text { Technical } \\
\text { problems }\end{array}$ & 1 & $1.02 \%$ & $7.69 \%$ \\
\hline \multicolumn{4}{|c|}{ Table 1 } \\
\hline
\end{tabular}

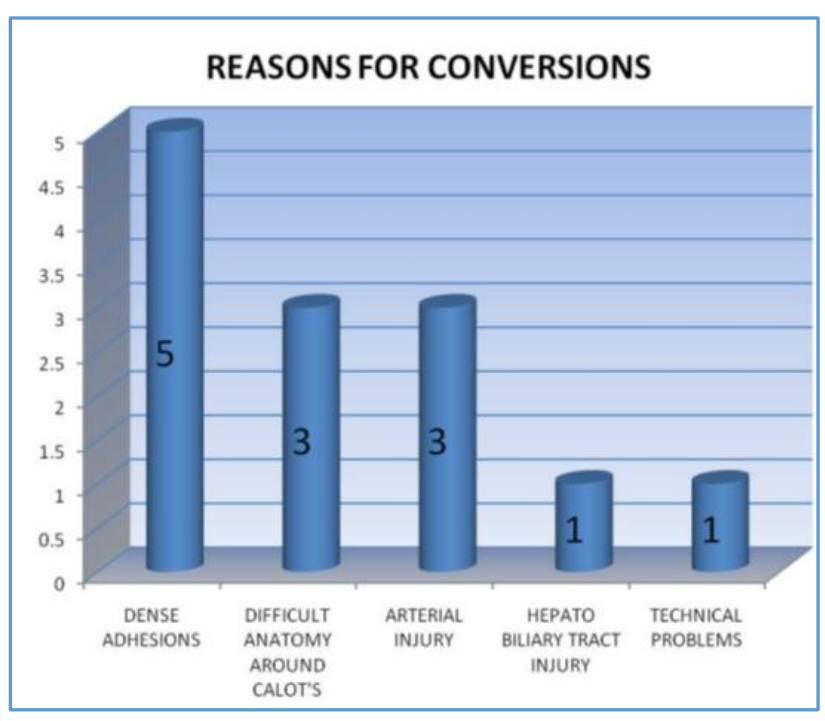

Chart 1

\begin{tabular}{|c|c|c|}
\hline & Converted Cases & \% of Total Cases \\
\hline Males & 6 & $6.12 \%$ \\
\hline Females & 7 & $7.14 \%$ \\
\hline Table 2. Incidence of Conversion among Males and \\
Females \\
\hline
\end{tabular}

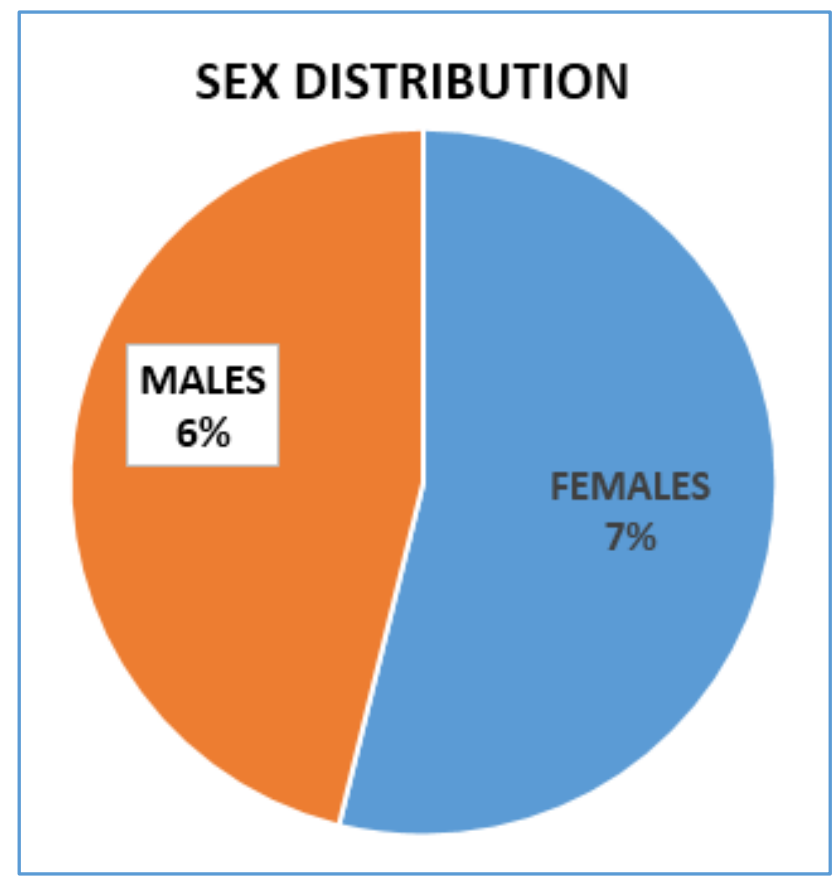

Chart 2

\begin{tabular}{|c|c|c|}
\hline Age Group & $\begin{array}{c}\text { Number of Cases } \\
\text { Converted }\end{array}$ & $\begin{array}{c}\text { \% of Converted } \\
\text { Cases }\end{array}$ \\
\hline $10-20$ & 0 & $0 \%$ \\
\hline $20-30$ & 3 & $23.07 \%$ \\
\hline $30-40$ & 2 & $15.08 \%$ \\
\hline $40-50$ & 6 & $46.15 \%$ \\
\hline $50-60$ & 2 & $15.38 \%$ \\
\hline $60-70$ & 0 & $0 \%$ \\
\hline
\end{tabular}

\section{DISCUSSION}

Studies from various countries reported a conversion rate of 5 to $14 \% .5,6,7,8,4,9,10,11$ In our study, 98 patients were operated over a period of 1 year from November 2016 - November 2017 and the conversion rate was $13.26 \%$. Several prospective studies $[12,13,14,15,16,9,10,11,17,18,19]$ have drawn results similar to our study.

\section{Dense Adhesions}

The conversion of laparoscopic cholecystectomy due to dense adhesions in our study is $5.1 \%$ of total cases that were operated and is $38.46 \%$ of cases that got converted. Even though the patients in our study have not undergone any previous upper abdomen surgeries, adhesions remained the most common cause for conversion. Studies by Ajay Anand, Raad S Al-Saafar et al of Al-Najaf Nadim Khan et al, NEJM Surgical Study Group and Saeed Hadi Al-Bahlooli[20,21,12,22,3] quoted that adhesions are the most common cause for conversion of laparoscopic cholecystectomy. In our study group, adhesions were found in 5 cases, of which adhesions between gall bladder and hepatic flexure of colon was found in 1 case, gall bladder and duodenum in 1 case, greater omentum and anterior abdominal wall in 2 cases and adhesions around porta hepatis in 1 case.

\section{Difficult Anatomy around Calot's Triangle}

The conversion of laparoscopic cholecystectomy due to difficult anatomy around Calot's triangle in our study is 3 cases $(3.06 \%)$ of total cases that were operated and is $23.07 \%$ of cases that got converted. The conversion of laparoscopic cholecystectomy is extremely important when there is difficult anatomy around Calot's triangle, as there is more chance of bile duct and cystic artery injury in this situation. In studies by Volkan Genc et al, Muhammed Shamim et al, SK Biswas et al, Singh Kuldhip et al, Saeed Hadi Al Bahlooli,[23,1,24,15,24,3,26] it was concluded that the conversion of laparoscopic cholecystectomy due to difficult anatomy around Calot's triangle is the most common cause for conversion of laparoscopic cholecystectomy. Anatomy can get altered due to any cause like acute cholecystitis, aberrations in cystic artery, right hepatic artery, common hepatic duct and common bile duct. In our case series there was excessive fat near the Calot's triangle in two cases, cystic artery identification was difficult.

\section{Arterial Injury}

The conversion of laparoscopic cholecystectomy due to arterial injury in our study is 3 cases $(3.06 \%)^{[20,12,24,25]}$ of total cases that were operated and is $23.07 \%$ of cases that got converted. It is one of the most important causes for conversion, as it produces immediate hypotension and even death if immediate intervention was not done. Usually, laparoscopic repair of the bleeding site is not done, because the field will become filled up with blood and most of the times 
it is impossible to identify the bleeding vessel in such a situation. Therefore, the only option that saves the patient in such condition is conversion. Blind application of clips or cauterisation in unclear area is absolutely contraindicated because of the potential danger of misplacing the clips or cautery to vital structures, the results of which may go hazardous to the patient's life. In our study cystic artery was injured in 2 cases because of difficult dissection near Calot's triangle and 1 case is due to aberrant origin of cystic artery from common hepatic artery. Another case is converted due to torrential bleeding from the liver bed after dissection of the gall bladder.

\section{Hepatobiliary Injury}

The conversion of laparoscopic cholecystectomy due to hepatobiliary injury in our study is 1 case $(1.02 \%)$ of total cases $[1,12,24,21]$ that were operated and is $7.69 \%$ of cases that got converted. It occurs mostly due to blind dissection near Calot's when anatomy is unclear. It requires high level of expertise and experience to identify hepatobiliary injury, as most of the times it is not identified per-operatively and diagnosed only in the post-operative period. But when there is suspicion intraoperatively, intraoperative cholangiogram is to be done whenever there is a possibility and repair to be done in the most appropriate way. At any cost bile leak should be prevented, as it possess a significant level of mortality when it causes biliary peritonitis.

\section{Technical Issues}

The conversion of laparoscopic cholecystectomy due to technical issues in our study is 1 case $(1.02 \%)$ of total cases that were operated and is $7.69 \%$ of cases that got converted. Very few of the conversions were due to technical issues like poor lighting, insufflator defects, unclear monitor/ cameras, defective dissectors/ graspers and diathermy handles. Conversion due to technical issues are going down even in the developing countries like ours. It assumes importance because it is one of the easily correctable causes to avoid a conversion. Studies from the eastern part of the world showed technical issues as a reason for conversion in some of the cases. In our study one case got converted to open technique, because of the problem with insufflator and non-replacement can be done at that time and hence proceeded to open method even before the dissection of gall bladder and cystic duct artery. It is entirely hazardous to operate with defective instruments and conversion is the better option in terms of patient safety.

Again, it is highlighted that the conversion of laparoscopic cholecystectomy should be viewed as a good cause in terms of patient safety rather than as a failure in terms of the surgeon skills.

\section{CONCLUSION}

After analysing the results of our study, we conclude that the incidence of conversion of laparoscopic cholecystectomy is $13.26 \%$.

\footnotetext{
The Reasons for Conversion in Descending Order of Frequency are-

1. Dense adhesions (5.1\%).

2. Difficult anatomy around Calot's triangle (3.06\%).

3. Arterial injury (3.06\%).

4. Hepatobiliary injury $(1.02 \%)$.

5. Technical issues (1.02\%).
}

\section{REFERENCES}

[1] Shamim M. Fatima and Baqai hospital after observing 1238 patients concluded that the conversion rate in laparoscopic cholecystectomy was 6\%(81 patients) of which Calots triangle adhesions-44, Arterial injury-11, Wide cystic duct -7, CBD injury-5, Equipment failure-9, Bowel injury-5. J Pak Med Assoc 2009;59(7):456.

[2] Gholipur C, Fakhree MBA, Shalchi RA, et al. Prediction of conversion of laparoscopic cholecystectomy to open surgery with artificial neural networks. BMC Surgery 2009;9:13.

[3] Al-Bahlooli SH, Al-Malahi A, Ghallab NH, et al. Yemen observed 650 patients and stated that the conversion rate in laparoscopic cholecystectomy was 8.3\% (59 patients), adhesions being the most common cause. University of Science and Technology Yemeni Journal for Medical Sciences Yemeni Journal for Medical Sciences 2009;1(3):1-8. www.ust.edu.ye http://www.med.ust.edu.ye/Journal/Journal.htm

[4] Gabriel R, Kumar S, Shrestha A. Evaluation of predictive factors for conversion of laparoscopic cholecystectomy. India in 2005 stated that the conversion rate in laparoscopic cholecystectomy was $26 \%$. Kathmandu Univ Med J 2009;7(25):26-30.

[5] Khan IA, El-Tiney OE. Laparoscopic cholecystectomy for acute cholecystitis. Can preoperative factors predict conversion? After analysis of 44 patients who underwent laparoscopic cholecystectomy for acute cholecystitis observed that the conversion rate in laparoscopic cholecystectomy was 23\%. Saudi Med J 2004;25(3):299-302.

[6] Pavlidis TE, Marakis GN, Ballas K, et al. Risk factors influencing conversion of laparoscopic to open cholecystectomy. In 2007 stated after studying 1263 patients that the conversion rate in laparoscopic cholecystectomy was $6.3 \%$. Journal of Laparoendoscopic \& Advanced Surgical Techniques 2007;17(4):414-8. https://doi.org/10.1089/lap.2006.0178,

[7] Alponat A, Kum CK, Koh BC, et al. Predictive factors for conversion of laparoscopic cholecystectomy. The conversion rate in laparoscopic cholecystectomy was 4\%. World Journal Surgery 1997;21(6):629-33.

[8] Malik A, Laghari AA, Talpur KAH, et al. Laparoscopic cholecystectomy in empyema of gall bladder: an experience at Liaquat University Hospital, Jamshoro, Pakistan. Quoted that the conversion rate in laparoscopic cholecystectomy was $19.4 \%$. Journal of Minimal Access Surgery 2007;3(2):52-6.

[9] Lo CM, Liu CL, Lai ECS, et al. Early versus delayed laparoscopic cholecystectomy for treatment of acute cholecystitis. After observing 500 patients concluded that the conversion rate in laparoscopic cholecystectomy was 9\%. Annals of Surgery 1996;223(1):37-42.

[10] Rosen M, Brody F, Ponsky J, et al. Predictive factors for conversion of laparoscopic cholecystectomy. In their study of 1347 patients in 2002 stated that the conversion rate in laparoscopic cholecystectomy was $5.3 \%$. The American Journal of Surgery 2002;184(3):254-8. 
[11] Morshed M, El-Awadi S, Khafagi W, et al. A comparison of laparoscopic and open cholecystectomy in patients with compensated cirrhosis and symptomtic gall stones. 1999 of Mansoura faculty of medicine observed that the conversion rate in laparoscopic cholecystectomy was 6\%. Egyptian Journal of Surgery 2003;22(3):249-55.

[12] Anand A, Pathania BS, Singh G. Conversion in laparoscopic cholecystectomy: an evaluation study. Observed 176 patients from 2002 to2003 and stated that the conversion rate in laparoscopic cholecystectomy was $11.93 \%$. (21 patients)Adhesions 8 (3.54\%) Bleeding - 5 (2.84\%) Unclear anatomy - 3 (1.70\%) CBD injury - 2 (1.14\%) Equipment failure - 3 (1.70\%). JK Science 2007;9(4):171-4.

[13] Lipman JM, Claridge JA, Haridas M, et al. Preoperative findings predict conversion from laparoscopic to open cholecystectomy. In quoted that the conversion rate in laparoscopic cholecystectomy was 34.8\%. Surgery 2007;142(4):556-65.

[14] Kuldhip S, Ohri A. Difficult laparoscopic cholecystectomy: a large series from north India. Quoted that the conversion rate in laparoscopic cholecystectomy was $12.2 \%$ and it is commonly due to adhesions. Indian Journal of Surgery 2006;68(4):205-8.

[15] Van der Steeg HJ, Alexander S, Houterman S, et al. Risk factors for conversion during laparoscopic cholecystectomy - experiences from a general teaching hospital. Netherland analysed 972 cases from 20002006 concluded that the conversion rate in laparoscopic cholecystectomy was $12 \%$ (121 patients). Scand J Surg 2011;100(3):169-73.

[16] Malla BR, Shrestha RKM. Laparoscopic cholecystectomy: complication and conversion rate. Katmandu University in 2009 stated that the conversion rate in laparoscopic cholecystectomy was 3.92\%. Kathmandu Univ Med J 2010;8(32):367-9. http://dx.doi.org/10.3126/kumj.v8i4.6232

[17] Gupta V, Chowdri N, Wani NA, et al. LAP V/S open cholecystectomy: a prospective study of 800 patients. SKIMS-India stated that the conversion rate in laparoscopic cholecystectomy was $7.5 \%$. JK Science 2009;11(1):11-5.

[18] Memon W, Khanzada TW, Samad A, et al. Complications of laparoscopic cholecystectomy at Isra University Hospital, Hyderabad. In 2008 observed that the conversion rate in laparoscopic cholecystectomy was $4 \%$ after study of 216 patients. Pak J Med Sci 2009;25(1):69-73.

[19] Ishizaki Y, Miwa K, Yoshimoto J, et al. Conversion of elective laparoscopic to open cholecystectomy between 1993 and 2004. Japan 2006 stated that the conversion rate in laparoscopic cholecystectomy was $5.3 \%$ after a study of 1179 patients. Br J Surg 2006;93(8):987-91.

[20] Al-Saafar RS, Al-Janabi FA, Al-Jubori AA, et al. Conversion rate in laparoscopic cholecystectomy: a review of 300 cases. Al-Najaf medical university after analyzing 300 cases from 2007 to 2009 stated that the conversion rate in laparoscopic cholecystectomy was $1.66 \%$, of which dense adhesions being the most common cause for conversion. Karbala J Med 2010;3(1):772-8.

[21] Thyagarajan M, Singh B, Thangasamy A, et al. Risk factors influencing conversion of laparoscopic cholecystectomy to open cholecystectomy. Proved Patient Related Factors - Age $>50$ yrs, Male gender, Presence of Diabetes Mellitus, Obesity, previous Abdominal surgeries and Disease Related Factors previous episode of Acute Cholecystitis, presence of Acute Cholecystitis, Gallbladder wall thickness $>4 \mathrm{~mm}$, presence of Pericholecystic fluid were found to be significant risk factors in conversion of laparoscopic to open cholecystectomy. Int Surg J 2017;4(10):3354-7.

[22] A prospective analysis of 1518 laproscopic cholecystectomies. The Southern Surgeons Club. 20 surgical groups analysed 1518 laparoscopic cholecystectomies and concluded that the conversion rate in laparoscopic cholecystectomy was $4.7 \%$ (72 patients) of which Adhesions - 36 (2.3\%)Aberrant anatomy - $6(0.4 \%)$ Bleeding - (5 $(0.3 \%)$ CBD injury 4 (0.3\%)Bowel , injury - 4 (0.3\%). N Engl J Med 1991;324(16):1073-8.

[23] Genc V, Sulaimanov M, Cipe G, et al. What necessitates the conversion to open cholecystectomy? A retrospective analysis of 5164 consecutive laparoscopic operations. Ankara Medical University, Turkey after analysing 5164 patients from 1999 to 2010 stated that the conversion rate in laparoscopic cholecystectomy was $3.16 \%$ and most of it was due adhesions of Calot's triangle. Clinics (Sao Paulo) 2011;66(3):417-20.

[24] Biswas SK, Saha JC, Rahman AS, et al. Rate of conversion and postoperative complications of laparoscopic cholecystectomy in district level hospital of Bangladesh. Bangladesh after analysing 760 patients from 2006 to 2011 observed that the conversion rate in laparoscopic cholecystectomy was $2.5 \%$ (19 patients) Calot's Adhesions - 6 (2.5\%) Bleeding - $2(0.26 \%)$ Acute cholecystitis - 5 (0.66\%) CBD injury - 3(0.40\%) Equipment failure - $3(0.40 \%)$. Faridpur Med Coll J 2011;6(2):74-7.

[25] Rooh-al-Muqim, Qutab-e-Alam J, Mohammad Z, et al. Complications of laproscopic cholecystectomy. Khyber hospital observed 351 patients from $2005-2007$ and concluded that the conversion rate in laparoscopic cholecystectomy was $3.13 \%$ (11 patients) Adhesions $3(0.85 \%)$ Altered anatomy - $3(0.85 \%)$ Bleeding - 5 (1. $43 \%)$. World Journal of Laparoscopic Surgery 2008;1(1):1-5.

[26] Memon MR, Muhammad G, Arshad S, et al. Study of open conversion in laparoscopic cholecystectomy. In 2010 stated that the conversion rate in laparoscopic cholecystectomy was $0.65 \%$ of which adhesions noted in $0.25 \%$. Gomal Journal of Medical Sciences 2011;9(1):51-4. 